\title{
(2. Experimental Pressure-Forming: Adding Value through Tooling Improvement, and a Hypothesis for Tooling Provision in Autonomous Development Environments
}

\section{Daniel Keith Elkin}

$130-149$
This paper describes improved pressure forming techniques, metal-forming methods related to industrial processes, but suited to lower capitalisation contracting or do-it-yourself (DIY) fabrication settings. Working from literature and previous research, the author describes advancements to the tooling's capabilities, compared to other research vectors for double-axis curvature metal forming. These works connect fabricators' situational constraints to value constructs that surround making's particularity as research, and to values driving autonomous development construction networks. This paper asks: what values drive, and what value is added by, improving such sub-optimal fabrication processes? Given industrial and digital processes' extensive capabilities, are there contexts where intermediate technologies are particularly suited? How do those contexts constrain technical researchers' ability to add

\#making research

\#tooling provision

\#metal forming

\#construction technology networks

\#autonomous development value through tooling improvement? This paper presents recent

technical research, and projects a method to integrate that

research into autonomous development fabrication contexts

within the Hong Kong Special Administrative Region (HKSAR)

and China's Great Bay Region. 


\section{Introduction}

This paper describes technical research into pressure forming metal sheet. Projections from this research suggest a hypothetical tooling provision methodology to test research implementation in existing housing development markets.. Pressure forming relates to industrial standard hydroforming processes, but with tooling size, cost, and complexity suited to lowercapitalisation contracting, owner-builder, or do-it-yourself (DIY) maker fabrication settings. Working from Philip Ayres ${ }^{1}$ research and popular publications on the tool, ${ }^{2}$ the author describes experimental improvements to the setup (Ayres and Sheil 2012; Mallet 2011).

Pressure forming methods are divided into free pressure forming (FPF) and die-driven pressure forming (DPF). The author describes improved FPF workflows that eliminate welding, increase repeatability, and reconcile the technique with construction technology norms. DPF improvements include reduced setup time, increased design intent form vocabulary, decreased spatial requirements, and better ergonomic design. The author connects these experimental developments to underpinning maker-researcher methodological context constraints. Tooling environment, ergonomic, and spatial impacts upon workmanship ${ }^{3}$ influence the maker-researcher's technological research, creating a distinct subset of technological research (Pye 2015).

Conceivably, this type of technological research is particularly applicable to the construction technology network (CTN) John F.C. Turner and his colleagues described (Fichter et. al 1972). The CTN is the supplier network underpinning housing development, particularly autonomous housing development, made up of small fabricators, contractors, and suppliers (Fichter 1972). ${ }^{4}$ As argued in this paper, CTN members face similar tooling environment, ergonomic, and spatial impacts upon workmanship to makerresearchers. Research among Hong Kong's small to medium enterprise (SME) metalworking community indicates that this part of Hong Kong's CTN feels the impacts of such limitations. Their willingness or unwillingness to undertake experimental metalworking commissions beyond their typical business practice correlates to tooling environment, ergonomic, and spatial constraints upon their workmanship (Elkin 2018). ${ }^{5}$ Conceivably this is because, distinct from more formalised parts of the production market, CTN members operate at low capitalisation, operate locally, and approach commissions in a narrow range of incremental, or post-occupancy design intents. Distinct from industrialised producers' relatively more straightforward comparisons between capitalisation and product output, the trade-offs for CTN technological improvement may be substantially different. CTN members likely compare marginal improvements in delivery certainty for design intents against tool rent, hazards, and proximate availability to their shops. Arguably, these relationships are similar to maker-researchers' relationships with tooling improvement: tooling that is available, that is safe and easy to operate, and that is spatiallypracticable may constitute more significant advancement in CTN and maker-researcher environments than any industrial production ideal, even if the tooling makes new design intents only marginally more feasible.

To test this hypothesis, this paper suggests a tooling provision methodology to transition makerresearcher efforts to CTN members' possessions. The author's forthcoming research in an autonomous housing development environment near Hong Kong suggests a location where new metalworking design intents could meaningfully transition into a CTN. Tai O, a fishing village near Hong Kong, is a rare example of resident-driven housing development in Hong Kong. Concrete 
"village houses" along the shore populate an estuary, along with wooden-framed, metal-clad stilt houses in the tidal zone (Wong 2000). Tooling environment, ergonomic, and spatial constraints strongly influence members of the Tai O CTN's ability to effect new design intents. Work with Tai O's shifu and stilt house building contractors will indicate their uses for the pressure forming tooling. To place the DPF and FPF tooling into their hands experimentally allows consequential characteristics of Tai O's CTN to generate information on the tool's implementation prospects. What uses for the tooling will they find? What improvements to the tooling might they suggest? More critically, will the tooling allow design intents responsive to substantive transition threats in Tai O's development market? Tai $\mathrm{O}$ is, after all, under threat from a complex series of environmental and legislative concerns (Lands Department 2016). As it negotiates a transition from a subsistence fishing economy to a tourism economy, demographic and developmental pressures likely prompt design intents beyond the CTN's typical course of business. Historic and cultural development concerns uniquely constrain the CTN's response options such that some transition assistance methods are inappropriate. Can researchers work with CTN members to negotiate this change? While DPF and FPF unlikely respond to threats other than wind and impact loading upon wall-sections, this first test of the tooling provision hypothesis will provide new information on marginal and particular factors that constrain a technological improvement within a CTN, constrained as it is by its circumstances and particular character.

\section{Advancements to the Tooling}

The author explored pressure forming, informed by Philip Ayres' writing on the technique, after previous research into Hong Kong's metalworking industry. The process uses fluid pressure, most often water but sometimes mineral oil hydraulic fluid, to deform metal sheets. The process is similar to inflating a water balloon. Ayres' and popular sources' techniques are divided into two sub-categories. Ayres' termed his method "freepressure forming" (FPF) which inflates a metal volume welded at the edges. Nothing constrains the inflation except the maker's discretion to halt the fluid flow, and the process creates unique, doubly curved metal volumes with shapes determined by the forming blank's flat geometry (Ayres and Sheil 2012). Other sources describe a die-driven process. Two-dimensional dies made from thick metal plates control sheet deformation as the fluid inflates them from below. This process, here termed die-driven pressure forming (DPF), constituted a second set of experimental fabrications.

Initial experiments in free-pressure forming removed welding from the workflow. A doubly hemmed, silicone caulk-filled edge at the edges of FPF blanks obviated perimeter welding as a means to contain fluid. This change makes FPF with galvanised, anodised, and electro-plated steel, or aluminium and copper sheets safer and more feasible. This also placed some limits on viable forming blank shapes. Bending flanges for hemmed edges on a curved forming blank forms compression or tension flanges, making closure between two forming blanks difficult. Eliminating welds between the forming blank and fluid source proved much more complicated. Durable, demountable, un-welded flanges required fastening the flange between two sides of a forming blank. This required the author to destroy the completed, inflated form to retrieve the water supply flange. The author developed a preliminary design for a demountable water supply based on a marine scupper plug. Initial prototypes successfully achieved a watertight, demountable seal between the forming blanks and the fluid supply. A subsequent purpose-built prototype will reduce the attachment opening size, reduce 
tooling clearance required for inflation, and reduce the pre-sinking required to insert the fluid supply. An Amada Turret Press with forming tooling also allowed experiments testing pre-formed linear patterns on forming blanks. This testing may allow increased control over free-pressure forming, but is so far inconclusive. This iteration of FPF results are effectively uncontrollable, apart from discretion over the degree of inflation and relationships between forming blank shape and resultant inflated shape. Ayres argued that the aesthetic uniqueness of the processes' output, along with labour discretion allowed by makers' control over fluid supply, compensated for this relative lack of control. Labour discretion, especially as a site-adaptability opportunity, could prove a useful characteristic for the technology with further development. Future research with FPF will focus on bringing the technology closer to construction industry norms. The process shown is presently viable with sheet thicknesses less than or equal to two millimetres, suggesting metal cladding, rather than structural applications. Integrating a rear mounting flange on FPF forming blanks, along with corner transitions and waterproofing describe further research vectors for the technology. Meanwhile, popular sources suggested that a similar pressure forming process would be more likely to address these construction technology requirements.

Die-driven pressure forming (DPF) allows metal shell production with a better balance between labour discretion, more certain delivery, and more easily implementable design intents. Relatively simple dies allow certain tile-able shape production and provide one flat surface to the shells, making the process outputs readily applicable as cladding. There is, however, considerable room for improvement to the tooling in its current state. A primary difficulty with DPF tooling as previously designed is the force required to deform a metal sheet. Two-dimensional metal dies between one and two centimetres thick must sit on one side of the forming blank, with a similar thickness bearing plate on the other side to control fluid pressure. This means the tool is usually too heavy for one- or two-person lifting if it is large enough to form metal shells of any significant size. The author's initial experiments, consequently, reside within a 40 centimetre by 20 centimetre rectangular area. This makes the tooling cartable by hand. The resultant doubly curved shells, applied as cladding, are closer to shingles than fully demountable panels. Panels would preferably be larger, and flanged for demountable attachments at top and bottom. The next iteration of the DPF tooling mounts bearing plates and dies on a mobile table to make the tool cartable at increased size. As space is a constant constraint in Hong Kong's crowded environment, where the author conducts research, hinges in the bottom bearing plate of the tool allow it to fold vertically and reduce transportation width. The deployed forming area of the tool will be 60 centimetres by 90 centimetres. The author derived these dimensions from the size of 55 gallon drums, and their constituent ergonomic suitability. Introducing an Ethylene Propylene Diene Monomer (EPDM) rubber membrane into the tool allowed perforated shell production in previous experiments. The future DPF rig will use a double-sided EPDM membrane. This will contain the forming fluid better than a linear gasket between the forming blank and bearing plate, and reduce potential corrosive contact between the fluid and the workpiece. While this will make plumbing the rig more difficult, it will provide dissemination-friendly advantages: it will obviate the need to tap the bottom plate for plumbing, and reduce the risk of marking the forming blank.

Designing the forming dies remains a site for additional feedback from contractors working in a project area. The shape chosen for the deforming metal to expand through unavoidably confines the range of formable outputs. With a broad range of design intents as a constraint, the tool includes 
multiple interchangeable dies. Generally, the die shapes chosen are tessellating shapes with 1:1 or 1:2 height-to-width ratios. Circular and elliptical dies, while not tile-able, allow parabolic mirror fabrication. The experimental arabesque-shape die is a tessellating shape informed by metal flange seaming experience. Minimising corners allows smoother transitions between flanges and seams, rationalising an otherwise-capricious-seeming panel shape. As a user must interchange dies, they should be as lightweight as possible, suggesting aluminium as a suitable material choice. Further, dividing dies into halves makes them easier to handle and transport, and allows shape combination. If possible, vinyl coating on top dies and bottom bearing plates will reduce corrosion and marking.

Achieving fixity during forming remains a challenge. Previous designs for the tool fix the top die to the bearing plate with bolts through the die, workpiece, and bearing plate, and nuts on the other side. This detail is expedient because of the hardware's ubiquity, but seems a major site for improvement because of the long setup and reset time required. Tapping the bottom plate to receive machine screws through the top die allows faster setup, but constrains die shape flexibility, especially since square and 1:2 rectangular die formats are desirable within one rig. The problem of through-holes in the workpiece also remains. Mounting holes for bolts or screws in the workpiece complicates flanging for making demountable panels. A rail for hold-down clamps seems a viable solution. Lead shot bags or other cartable weights are also expedient, though a more weight-effective solution to provide fixity may be a powerful electromagnet. Protected by vinyl or silicone, an electromagnetic ring could force the halves of top dies together, and push them against the bearing plate to direct forming pressure. If electromagnet experiments work, the total elimination of mounting holes, and the obstructive clamp-mounting rail, could allow much more expressive fabrications. This method to achieve fixity would allow multiple forming operations within a single sheet, along with the anticipated vocabulary of repeating panels. The operator's labour discretion would totally control site and expansion of the metal to create a strongly expressive language. Furthermore, the electromagnet may prove the most promising part of the tool if made at once flexible before engaging power, and very rigid when powered. An electromagnetic chain-die may leave user discretion and the length of the chain itself as the only constraints on the tool's form vocabulary.

\section{The Maker-Researcher Methodology and Accompanying Value Sets}

The author conducted these experiments as a maker-researcher. To distinguish the maker from the designer, fabricator, or other members of the production economy requires an understanding of his or her fabrication context and priorities. As described in literature on the "maker movement" and other contexts of non-industrialised and/or formalised fabrication work, the maker:

1. Makes objects in a capacity not central to his or her primary employment, as distinct from the fabricator or contractor.

2. Participates personally in fabrication processes, applying her or his personal workmanship to artefacts. Potentially he or she applies this workmanship to artefacts further downstream than delineation or prototyping, even to final artefacts, as distinct from the formalised designer-delineator.

3. Makes use of informal or personally procured fabrication plant and environments, such as maker-spaces, home fabrication or community facilities (Conrad 2017). ${ }^{6}$ 
Making-research literature, as a subset within design research, emphasises values that differentiate between designers who make things from designers who do not. These circumstances somewhat modify each of the three points above. First, personal makers engage in production distinct from their primary employment as a hobby or secondary interest. Maker-researchers' object production is secondary because knowledge production is their primary concern. This partially complicates point two. Personal workmanship participation underpins the making-research versus design-research distinction. Given that knowledge production is the goal, this personal preference could stand in the way, conceivably of producing relevant, transferable, new knowledge. For instance, should the makerresearcher not seek the maximum workmanship competency available to ensure that research artefacts contribute to technology research's boundary knowledge production? Is their personal workmanship participation not an arbitrary preference or starting bias? Point three is similarly problematic: Should research not seek facilities appropriate to the technological state of the art, rather than depending on background availability and the researcher's personal facility?

Maker-research literature answers this question by privileging certain knowledge generation subsets emergent through personal workmanship participation rather than personal workmanship participation itself. Immediacy and responsiveness between design and fabrication, ${ }^{7}$ and the knowledge generated thereby, more closely encapsulate the rationale for maker-researchers' personal participation bias than arbitrary preference. Ayres and other authors describe unique knowledge sets emergent from this kind of relationship, both in terms of form production and research innovation (West and Sheil 2012; Carpenter and Hoffman 1997). Maker-researchers generate knowledge by designing through making rather than designing before making.
The process of workmanship itself is as much a site for knowledge generation as the outcome of workmanship. As a result, they may face facility and workmanship constraints similar to colloquial makers, but for different reasons. A personal or hobby maker's facility constraints depend on simple availability. A maker-researchers' facility constraints depend on immediacy, to the point that they may privilege more responsive facilities over more capable facilities, even if both are similarly available to him or her. Therefore, maker-researchers:

1. Make objects in an experimental capacity to contribute to a larger body of knowledge. As distinct from the fabricator, the knowledge, not the object, is the output of the work. This knowledge must contribute and disseminate through larger knowledge generation frameworks as research.

2. Contribute personal workmanship to objects to generate knowledge through immediacy and responsiveness between design and fabrication. As such, maker-researchers may forgo personal workmanship participation when facilities and fabricators are suitably responsive as well as capable.

3. Patronise or develop informal production facilities to the extent those facilities provide greater immediacy and responsiveness between design and fabrication. As such, a maker-researcher's facility preferences may alternate between informal and formalised stateof-the-art facility requirements.

Because of these biases, maker-researchers, compared to other technological researchers, conceivably face greater impact from tooling environment, ergonomic, and spatial impacts upon workmanship. ${ }^{8}$ A maker-researchers' directive for responsiveness and personal workmanship may mean tools that are available are preferred over 
tools that are most fully effective or efficiently productive (Elkin 2018). Immediacy may mandate working independently or personally providing workmanship to the extent of one's ability. This means hazards, lifting weights, and carting sizes directly affect the content and outcomes of the work. Informal facilities may be more responsive than formalised production facilities, constraining the maker-researcher's technological advancements to what fits in their domestic environment or incidentally available spaces. Their mandate for personal workmanship may disconnect their research from the prevailing plant or state of the art in technological research under some circumstances. While these constraints may seem artificial, or simply the result of poor funding and facilities to be improved, they may contribute to a certain subset of technological research as knowledge. Further, as discussed below, they may be uniquely applicable to a particular setting in real estate economy supply chains.

The author's experimental pressure-forming improvements evidence the import of these making-research constraints for technological improvement. The genesis for the research itself began from a tooling environment constraint upon both the author and other fabricators in his immediate context. Tooling and workmanship to produce doubly curved metal fabrications reliably is rare in Hong Kong, nominally nonexistent with the exception of rare shifu old masters possessing considerable skill (Elkin 2018). To explore this range of design intents with any degree of responsiveness and immediacy required new tooling, or a considerable improvement in the author's workmanship. With the latter yet to materialise, pressure forming experiments work to surmount this barrier into a responsive and iterative workflow. Similarly, while welders are somewhat common, three-phase electrical outlets are not available in most apartments or even many research facilities. Ayre's previous pressure forming work depends instrumentally on this tooling (Ayres and Sheil 2012). Along with considerable workmanship requirements, this tooling is situationally rare. The prevalence of galvanised and electro-plated steel sheet for Hong Kong's suppliers readily transitions into the second constraint set that maker-researchers face, i.e. ergonomic constraints. Welding galvanised steel sheet is possible and, in Hong Kong's metalworking shops, even common. However, results are categorically poor and, more importantly, this operation vaporises the zinc coating on the steel, which creates hazardous fumes. To be clear, ergonomic constraints are not solely construable as hazards. Simple facts of self-production guide the maker-researcher's technological innovation vectors. The author typically works alone. As a result, solutions to the original tooling constraint must tangibly respond: DPF dies must be light enough to lift. Deployment of the tools must be convenient, safe, and comfortable. Workflow constraints to reduce bending and lifting put the tool at table height. The author fillets or smooths edges when possible, not for aesthetic purposes but out of concern for the worker's hands. This concern, while hypothetically meaningful in all production scenarios, must be consequential for the maker-researcher as the distance between researcher, worker, and designer is zero. Lastly, spatial constraints provide research criteria seemingly contradictory to the tooling improvement brief, and yet critically important to the new technology's implementation. The tooling must fit through a door. The tooling must be mobile. The tooling must survive difficult outdoor and site conditions, as it cannot be stored in the author's living space.

In normative or industrial production contexts, many of these constraints would solely be present through complex and reified regulatory structures. Production technology advancement at the state of the art holds delivery certainty and quantity as its primary concerns and demands that, whenever possible, circumstances must change to make the 
technology viable. Industrial tooling progression discussed in engineering texts and construction technology literature suggests this as a widespread industry bias (Roser 2017; Ganesan et al. 1996). Producers and researchers must purchase and concentrate ancillary tooling to improve delivery certainty and capacity. Producers and researchers must improve human bodies past their ergonomic constraints, or work to omit them entirely. Producers and researchers must expand or build purpose-designed facilities to accommodate production. Conversely, in the context of makerresearchers' practice, technology must adapt to fit the circumstances. Increased delivery certainty remains a goal, but circumstantial and situational constraints temper the meaning of this goal. Efficiency, in terms of units of output per unit of time, may be a less critical concern. Certain design intents may remain unachievable without significant workmanship quality improvements, while still becoming more feasible than before technology improvement. With complex preconditions compared to the industrial norm, are there circumstances under which this makingresearch method can objectively add value? Can researchers conceive of making-research, an almost intentionally sub-optimised condition, as a subset of technological research with broad applicability?

\section{Making-Research and CTN's Shared Values}

To answer this question one could ask if there are subsets of the production market where available tooling, ergonomic, and spatial circumstances' impacts upon workmanship are meaningful to producers or the consumers they serve. Previous research into Hong Kong's metalworking industry revealed a market of fabricators contributing to what John F.C. Turner termed the "construction technology network" (CTN) (Fichter et. al 1972). CTNs are distinct from other production contexts in that they:
1. Operate at low to medium capitalisation, often dependent on marginal profit from additional commissions within a range of design intents determined by their initial tooling investment.

2. Operate locally or semi-locally, with geographic constraints on members' plant located closely to their consumer base and, often, within members' place of residency.

3. Operate diffusely, consisting of diverse members, with decentralised plant, marketing, motivations and capabilities (Ibid).

Hong Kong's metalworkers, SME fabricators engaged in small-scale fabrication and repair, often fit within these criteria. According to a survey, these metalworkers often work out of one shop within the Hong Kong area. Some have expanded to regional fabrication facilities in neighbouring cities in south China, but most operate in the same neighbourhoods for the extent of their business operation, often over the course of decades. Their added value to the consumers they serve depends on their possession of one or two critical articles of plant, typically a press-brake and/or a welder. They operate independently and seek postoccupancy or single-term commissions in a limited range of design intents, often ductwork production or furnishing commissions.

Experimental design commissions meant to test their production capability found strong correlations between tooling environment, ergonomic, and spatial constraints, and these businesses' willingness to accept new design intents. For example, fabricators were more willing to take on commissions with holes punched in the centre of a workpiece if highwattage laser cutter tooling was readily available 
to them, correlating this tooling availability to the design intent's delivery certainty. Designing commissions to remove welding from the production workflow increased the number of fabricators who were willing to take them on. Critically, no fabricators would accept experimental commissions requiring double-curvature metal forming without significant upstreaming assistance. Researchers provided additional computer numerically controlled (CNC) mill tooling and developed a forming buck, ${ }^{9}$ after which one fabricator was willing to accept the commission. Such tooling was nominally unavailable to metalworking professionals until researchers provided it. Ergonomic and spatial constraints upon fabrication commissions were intermingled. Fabricators tended to accept commissions more readily if the commissions were subdivided into cartable pieces, preferably under the size and weight of a one-person lift. Given that many fabricators in Hong Kong conduct their work in the street because of small workshop size, commissions that fabricators could assemble on a small table top achieved better results and more certain delivery (Elkin 2018).

In short, the tooling limitations, ergonomic constraints, and spatial constraints Hong Kong's metalworkers face strongly correlate to their willingness and ability to deliver design intents at the boundary of their capabilities. Such constraints are often external to design and research concerns outside the context of SME fabricators and members of a CTN. For certain, transitions into more formalised fabrication environments throughout south China allows these concerns to be secondary or even ignored. As such, correlations between market formalisation, geographic alienation, and reification of material labour constraints are conceivably present. More importantly, technological research through a maker-research framework, responsible to constraints that
CTN members share, may allow new insight into technological improvement vectors. The imperatives of normative industrial production may come secondary, when technology implementation is concerned, to the granular constraints upon CTN members' workflow. What is required is a methodology to test this hypothesis, and determine if this connection between makerresearch contexts and CTN contexts provides valuable insight.

\section{Tooling Provision into a CTN}

Land, materials, tools, labour, and financing are the resources that underpin the housing development market, according to Turner and his research colleagues. Within this market, Turner separates development planning and development action, and suggests, most critically, that research professionals conduct something more akin to planning. As planners, researchers concern themselves with limit setting and resource provisioning, not designing or employing resources as uniquely privileged development actors. To use Turner's analogy, researchers are "rule-makers," not "game players" (Turner 1972). Within this framework, the author hypothesises the next step in this research as a tooling provision methodology. The underlying research question is this: how can researchers help CTN members achieve meaningful design intents beyond their current capability? The hypothesis is that tooling provision, along with consultation as a form of labour provision, will lower opportunity costs for CTN members to achieve new design intents, through precise understanding of their circumstances.

Tooling provision encapsulates the expanded scope of this work as a context transition methodology. The content of the previous research, rather than the particular characteristics of the development context, sug- 
gests this method. Any large-scale resource provision, particularly pertaining to land, labour, or financing, is beyond the scope of this work. While this means the rationale for choosing this methodology is somewhat post-rationalised from the initial experiments, the site chosen for the initial case study to test this hypothesis suggests constraints upon the CTN that make tooling provision particularly suitable.

Tai O, a fishing village under HKSAR governance, is undergoing a development transition. Ambient development changes, along with Hong Kong Government Civil Engineering and Development Department (CEDD) planning strategy, describe a future role for Tai $O$ as an eco-tourism destination (Civil Engineering and Development Department 2017). Planners can predict demographic, land-use, and spatial programming changes under these circumstances, for areas developed as concrete "village houses" and areas comprising the original "stilt houses" that attracted tourism to Tai O (Wong 2000). Some are already underway: stakeholders note the repurposing of some stilt houses to guest rentals and bars, and other stilt houses rebuilt after fires have increased in both gross floor area and population density. ${ }^{10}$ Paradoxically, two factors constrain development growth within the original village's stilt house technology: first, the Lands Department (LD) mandates any stilt house renovation or construction to use "temporary materials," usually interpreted as wood and metal, not concrete (Lands Department 2016). Second, tourism objectives suggest that redevelopment with exogenous materials or technology would damage the overall appeal of the village's stilt house community. For residents to participate fully, Tai O CTN members are likely to require new design intents to accommodate the development transition: fireproofing and structural stiffening to address densification and commercial land uses, or larger floor and roof framing spans to accommodate assembly spaces. Notably, any material provision must strategically remain within Tai O's technological language. Additionally, the housing development change underway is not so much more housing development, but transitional housing development. This complexity, combined with interviewed stakeholders' exhortations that Tai $O$ residents are cash rich, and complex land tenure and taxation structures, suggest that financial subsidies for CTN members would require strategic trade-offs for implementation.

This leaves labour and tool provision as valuable techniques for implementing change. While providing additional labour as a numerical resource is beyond the scope of this work, labour provision as a technical or skill resource may be viable. Under Turner's instruction to work with residents not for residents, consultation with CTN members, providing skill and knowledge to reduce their opportunity cost, may make the difference in achieving new design intents for Tai O's transition (Turner 1972). However, such expertise provision or consultation strategies create knowledge transfer packaging and dissemination problems. Without either sophisticated representation packaging or continued correspondence with the development market, researchers' expertise may not transfer properly to more than one set of development actors. At this point, the researchers' work transitions from provision to action, dissemination becomes less likely, and political problems may result. Tooling provisions have the advantage of packaging research knowledge transfer as tacit knowledge, something consultation approaches struggle to do. A tool makes accomplishing certain design intents more feasible through its physical character. If placed correctly, at significant barriers in CTN members' capabilities, they provide specific and pre-validated solutions to fabrication problems. In exchange, researchers must package these solutions to a specific purpose: the tool must be designed to resolve 
a given range of design intents and do so well. As such, what constitutes a meaningful new design intent to CTN members and residents? becomes a critical question. Planners and researchers must ensure that tooling provision investments justify the trade-off between purpose specificity and fabrication feasibility, along with embodied capital for technology development itself. Arguably, the answer to this question lies in response to the demographic and development transitions described above, and in critical technologies that address those changes.

In response to these transitions, the pressure forming tooling is unlikely to be convincing. In the present iteration, the pressure forming tools allow doubly curved fabrications applicable as exterior cladding. Applied throughout Tai O's CTN these may allow more impact- and wind-resistant wall sections, which would likely be a relevant improvement given Tai O's coastal location. Parabolic mirrors could be useful for directing solar energy as well, contributing to electricity generation, heating, or food and clothes drying purposes. In spite of these limited applications, one virtue of the tooling provision methodology itself, however, is to remove some portion of pre-rationalisation from the development of the technology. That is, if the author deploys the pressure forming tooling in Tai $\mathrm{O}$, into the hands and control of Tai O's shifu and contractors, their decisions will determine its relevant use. With time, their deployment of the tooling will likely generate unexpected uses and new design intents. At a minimum, their work with the tooling, or even refusal to use it, will provide meaningful research feedback. Turner's methodology-cum-polemic for dealing with housing development in general and underserved populations in particular depends upon respect for and responsibility to these potentials for innovation feedback. As such, to surrender some degree of control and allow others to influence the outcome becomes an essential part of the research. For the maker-researcher and the technological researcher more broadly, this is conceivably a problematic demand: the desire to improve can run contrary to a mandate to listen, facilitate, and support. Upon testing, the tooling provision methodology works to bridge some of these difficulties: it works to connect maker-researchers' skills to package, improve, and solve CTN members' needs for autonomy, flexibility, and robustness. To accomplish this goal, this methodology concentrates makerresearchers' work on tooling design rather than assembly design, using their unique insights to connect technological research in the context of autonomous housing development. Forthcoming research will determine the viability and potentials of this approach. 


\section{Notes}

1. Ayres discusses what he calls "the persistent model," a hydroforming project whose form and spatial expression responded according to the pressure forming tool operator's first-hand decision-making. Ayres' approach is similar to popular publications on free pressure forming that uses stainless steel forming blanks, welded along their perimeter using, most often, tungsten inert gas (TIG) welding. Discussed in: Ayres, Phil, and Bob Sheil. "Microstructure, Macrostructure, and the Steering of Material Proclivities." In Manufacturing the Bespoke: Making and Prototyping Architecture, 220-37. Chichester, U.K.: John Wiley and Sons, 2012.

2. Among others, the Discovery Channel shows Mythbusters used the pressure forming technique to make doublycurved metal torpedo shells more expediently. From: Mallett, Jessica, writer. "Mythbusters Torpedo Tastic." In Mythbusters. Discovery Channel. 5 April, 2011.

3. David Pye defines a number of concepts related to workmanship: a worker's dexterity and patience generally control workmanship quality, taken as a comparison between the workmanship outcome and the design intent. Free workmanship, as opposed to regulated workmanship, allows some relaxation of a worker's dexterity within an acceptable outcome range. Certain workmanship refers to workflows where a worker's dexterity and patience during production impact the outcome's acceptability less than dexterity and patience before production. Uncertain workmanship depends upon skilled workmanship during production, as fewer controls are implemented beforehand. Pye's arguments de-couple certain value judgments for workmanship, particularly assumptions that regulated and certain workmanship equate to good workmanship. Pye stresses that workmanship's relationship to design intent allows a more complex interpretation of workmanship quality. From: Pye, David. The Nature and Art of Workmanship. New York: Bloomsbury, 2015.

4. Fichter, Turner, and Grenell describe CTN operations and constraints at length in Freedom to Build. Notably they suggest that CTN's diffuse character as a resourcemanaging structure is beneficial, in terms of arrangement, to residents, as well as the most common condition for residential construction economies. Refer to: Fichter, Robert, John F.C. Turner, and Peter Grenell. "The Necessity for Networks." In Freedom to Build: Dweller Control of the Housing Process, by John F. C. Turner and Robert Fichter, 255-274. New York: Macmillan, 1972.

5. Refer to the author's index study of small to medium metal working enterprises in: Elkin, Daniel. "Undevelopable: Metal, Curvature, and Tooling-Based Research in Hong Kong's Compressed Space." In 2018 Architecture and Civil Engineering Conference. Proceedings of Architectural and Civil Engineering Conference, Singapore. 2018. DOI: 10.5176/2301-394X_ACE18.114.
6. Literature on the "maker movement" describes the informal fabrication culture emerging in recent decades, such as: Conrad, Dale Dougherty. FREE TO MAKE: How the Maker Movement Is Changing Our Schools, Our Jobs, and Our Minds. READHOWYOUWANT, 2017. Some authors connected the maker movement with new forms of economic and real estate development, such as: Hirshberg, Peter, Dale Dougherty, and Marcia Kadanoff. Maker City: A Practical Guide To Reinventing Our Cities. San Francisco: Maker Media, 2017.

7. Mark West's initial interest in fabric-formed concrete work stemmed from a search for semi-determinate fabrication processes, allowing faster and more responsive feedback between design and fabrication. West, Mark, and Bob Sheil. "The Projective Cast." In Manufacturing the Bespoke: Making and Prototyping Architecture, 132-45. Chichester, U.K.: John Wiley and Sons, 2012. Similarly, multiple authors describe benefits to a responsive designing and making process in: Carpenter, William J., and Dan Hoffman. Learning by Building: Design and Construction in Architectural Education. New York: Van Nostrand Reinhold, 1997.

8. Similar relationships exist between spatial and ergonomic production constraints and their consumption, particularly by underserved populations in informal spatialisation contexts. Refer to: Elkin, Daniel, Gerhard Bruyns, and Peter Hasdell. "Appropriate Construction Technologies for Design Activism: Material Research Practices in Response to Globalisation." Architectural Research Quarterly 22, no. 4 (2018): 290-309. doi:10.1017/s1359135518000507.

9. Refer to practical references for metal forming either by hammering, or on an English Wheel and a buck to ensure design intent delivery in: Lipton, Tom. Metalworking Sink or Swim: Tips and Tricks for Machinists, Welders, and Fabricators. New York: Industrial Press, 2009.

10. This information is taken from an interview with Madame Wong Wai King, author of one of the primary texts about the history and anthropology of Tai $\mathrm{O}$. 

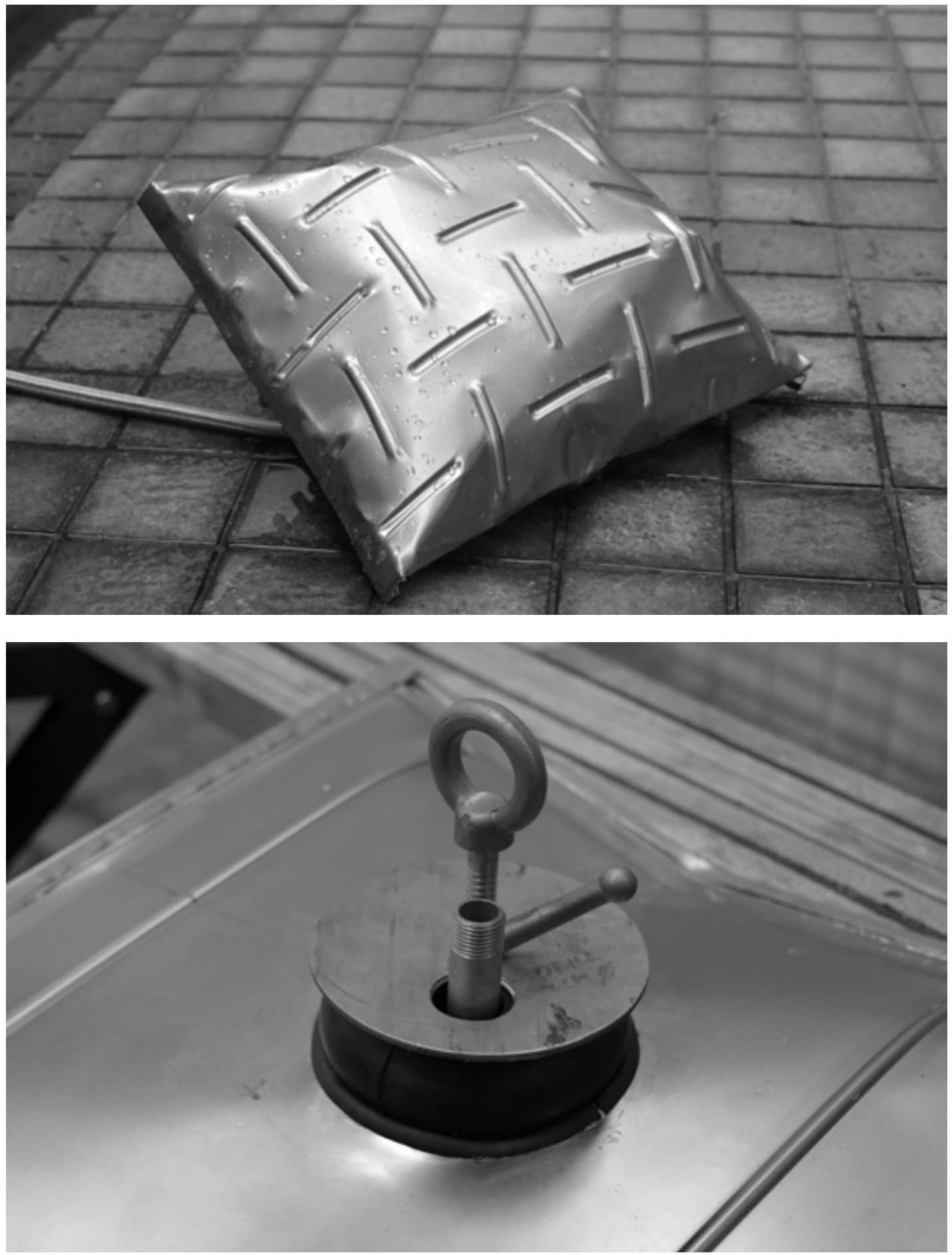


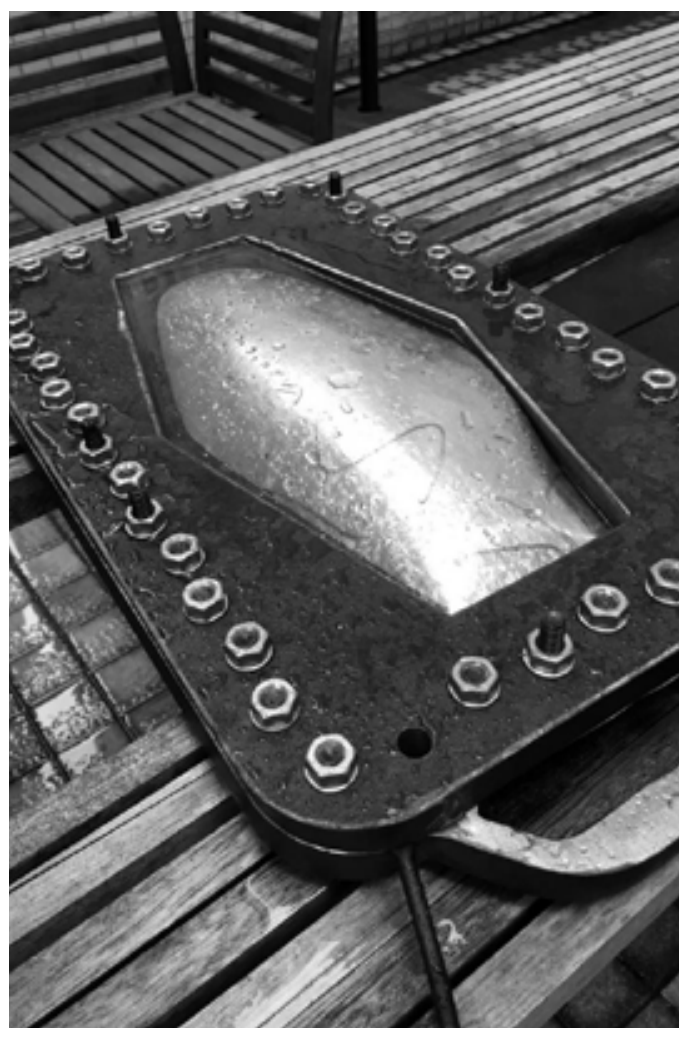

Figure 1 (top, opposite page): Early free-pressure forming test. This test successfully removed welding from the workflow, a desirable change for application to galvanised, anodised, or otherwise pre-coated metals that make welding dangerous or impossible. However, the through-bolted attachment flange on the rear of this test is not removable without destroying the final fabrication. Source: author.

Figure 2 (bottom, opposite page): Modified marine scupper plug, allowing demountable water pressure supply for free pressure forming. A rubber gasket adhered to the edges of a hole allows inflation of the metal volume without trapping the water supply attachment inside. To reduce the size of the entry aperture requires a custom attachment, necessitating more investment and better rationalisation of the technology. This is the author's most recent work on free pressure forming, as die-constrained forming has become the primary focus. Source: author.

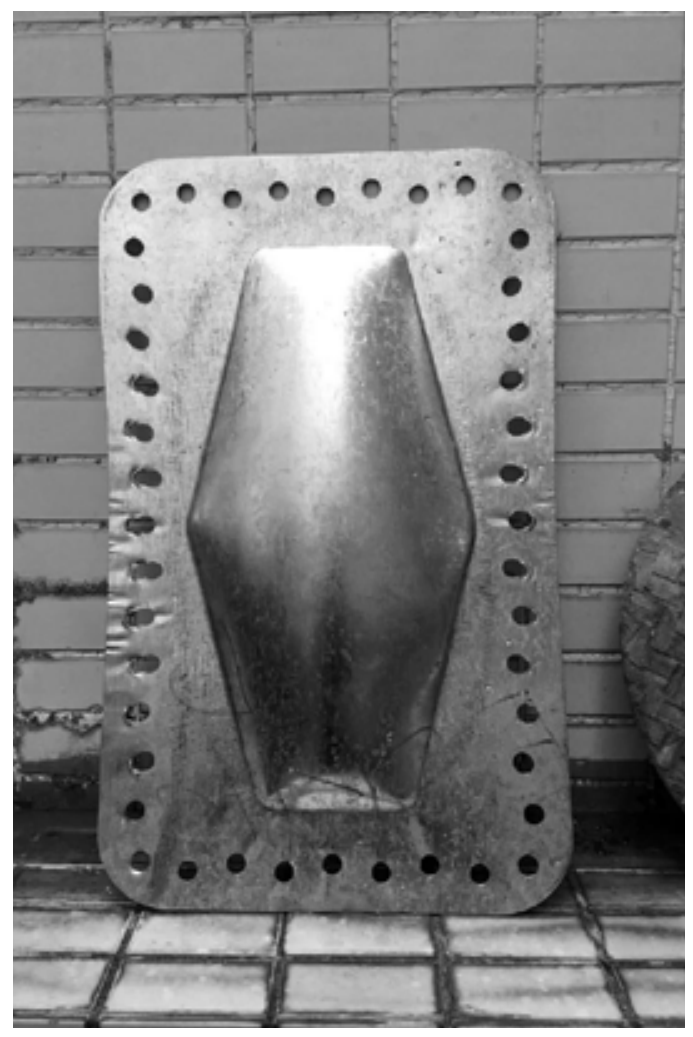

Figure 3 (left): Current pressure forming rig, with a hexagonshaped forming die. Source: author.

Figure 4 (right): Resultant hexagonal formed shell. As Ayres pointed out, one distinctive quality of the pressure forming process is that deformation amount is at the user's discretion up to the limit of the material, allowing labour discretion into the fabrication and design process. Note the deformation of the sheet near the through-holes for bolting the forming rig together. These make flanging for demountable panels difficult, making elimination of this fixing method a priority. Source: author. 


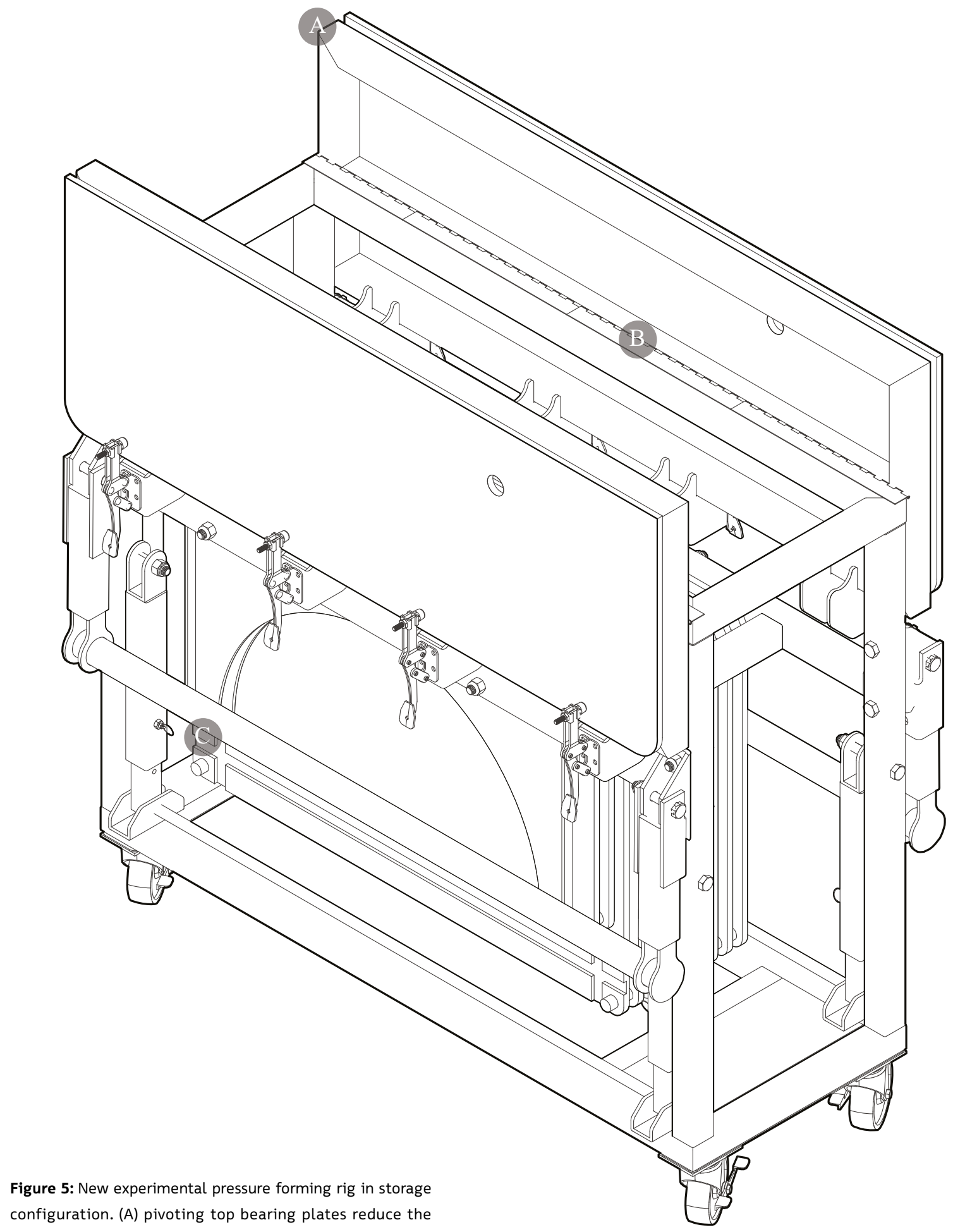
stored width of the rig to forty centimetres wide from a deployed width of around 80 centimetres. (B) continuous hinges allow operable top bearing plates. (C) die plates stored underneath the rig support have rubber bumpers to prevent noise and vibration. Source: author. 


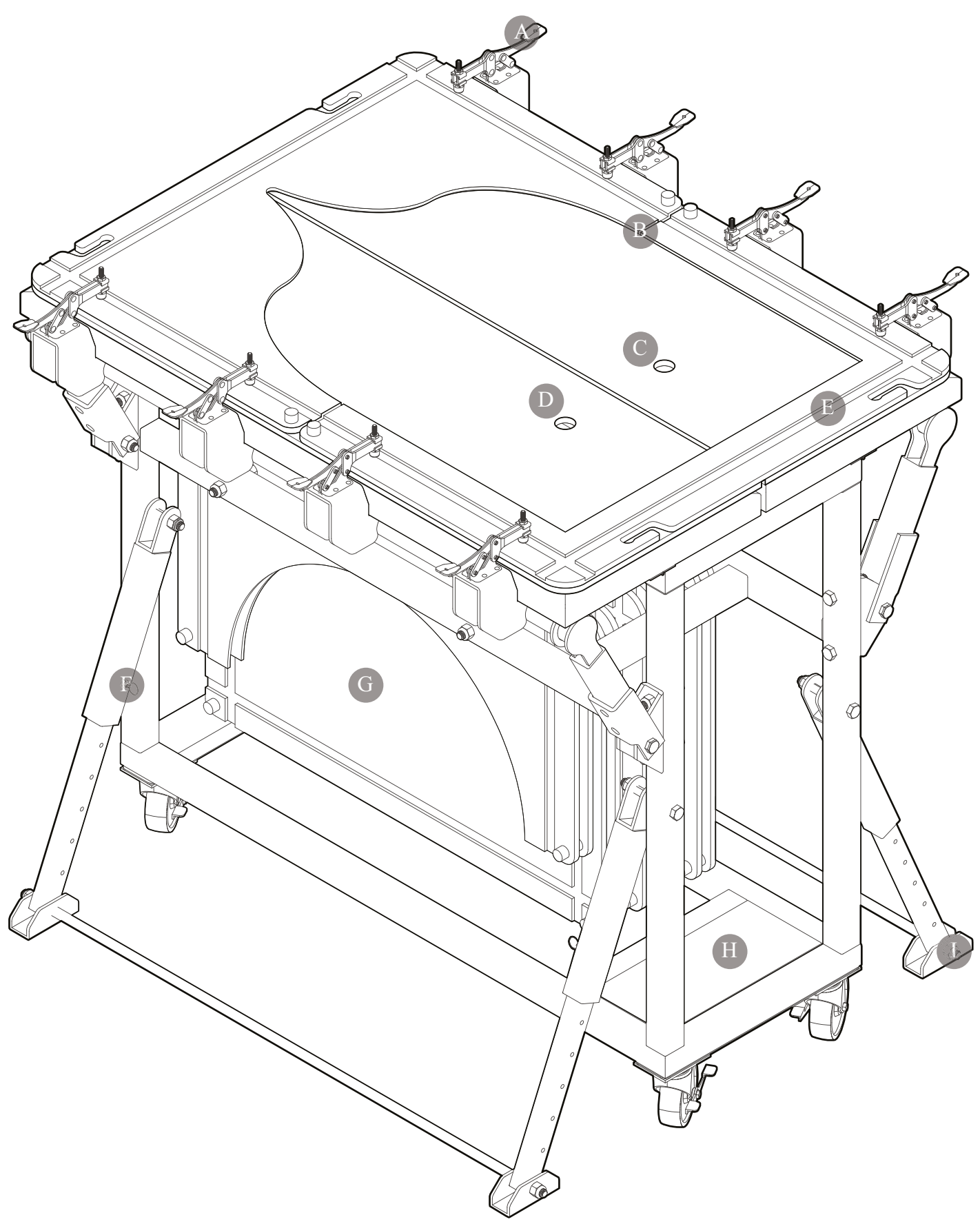

Figure 6: New experimental pressure forming rig in deployed formation. (A) flanges for demountable holddown clamps provide backup fixity in the event that the electromagnet design does not work or electrical current density is a site-condition issue. (B) stiff rubber gaskets at die jointures will allow inter-changeable dies with multiple configurations. (C) water inlet through bottom bearing plate into double-sided rubber forming bladder (not shown). (D) water outlet pressure release safety valve from double-sided rubber forming bladder. (E) milled pocket for electromagnet fixing frame. (F) telescoping stabilisation strut spring-pin. $(G)$ hanging storage for forming dies.(H) storage surface for pressure washer/pump. (I) stabilisation strut levelling foot. Source: author. 


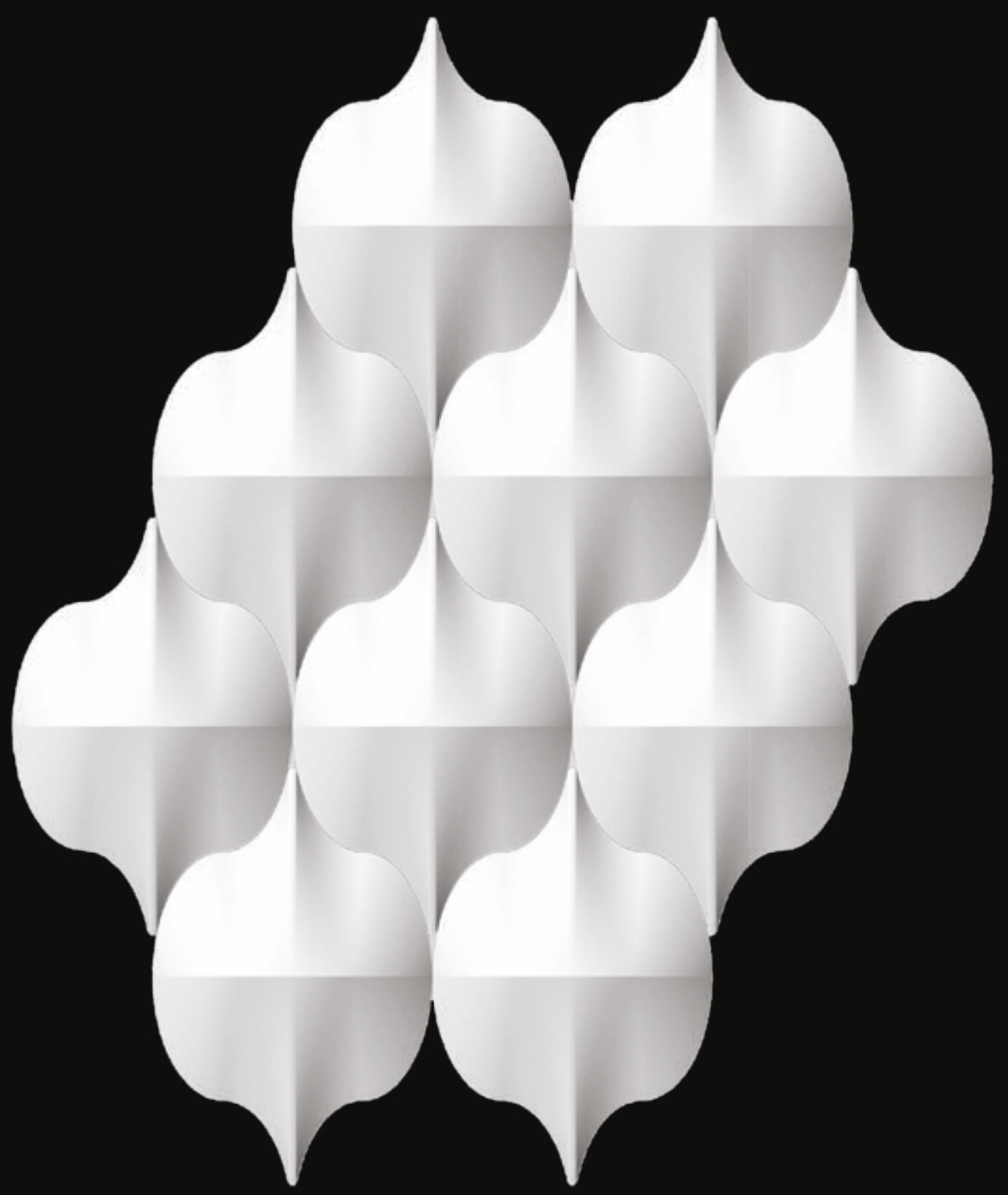

Figure 7: Arabesque panelling layout using identical die halves. Tessellating, curved panel shapes eliminate corners to respond to sheet metal forming constraints, where flanges perpendicular to the primary panel surface require joinery whenever an obtuse angle of incidence results. For example, hexagonal panels, which minimise the panels' perimeter length/surface coverage ratio also require more complex seaming operations between flanges. Partial panels at surface edges remain an issue, but the packing-readiness and fabrication suitability of the formed panels rationalise an otherwise capricious-seeming panel layout. Source: author.
Figure 8 (opposite page): Interchangeable die-halves allow combined panel configurations, making further rationalisation of other panel arrangements possible. Source: author. 


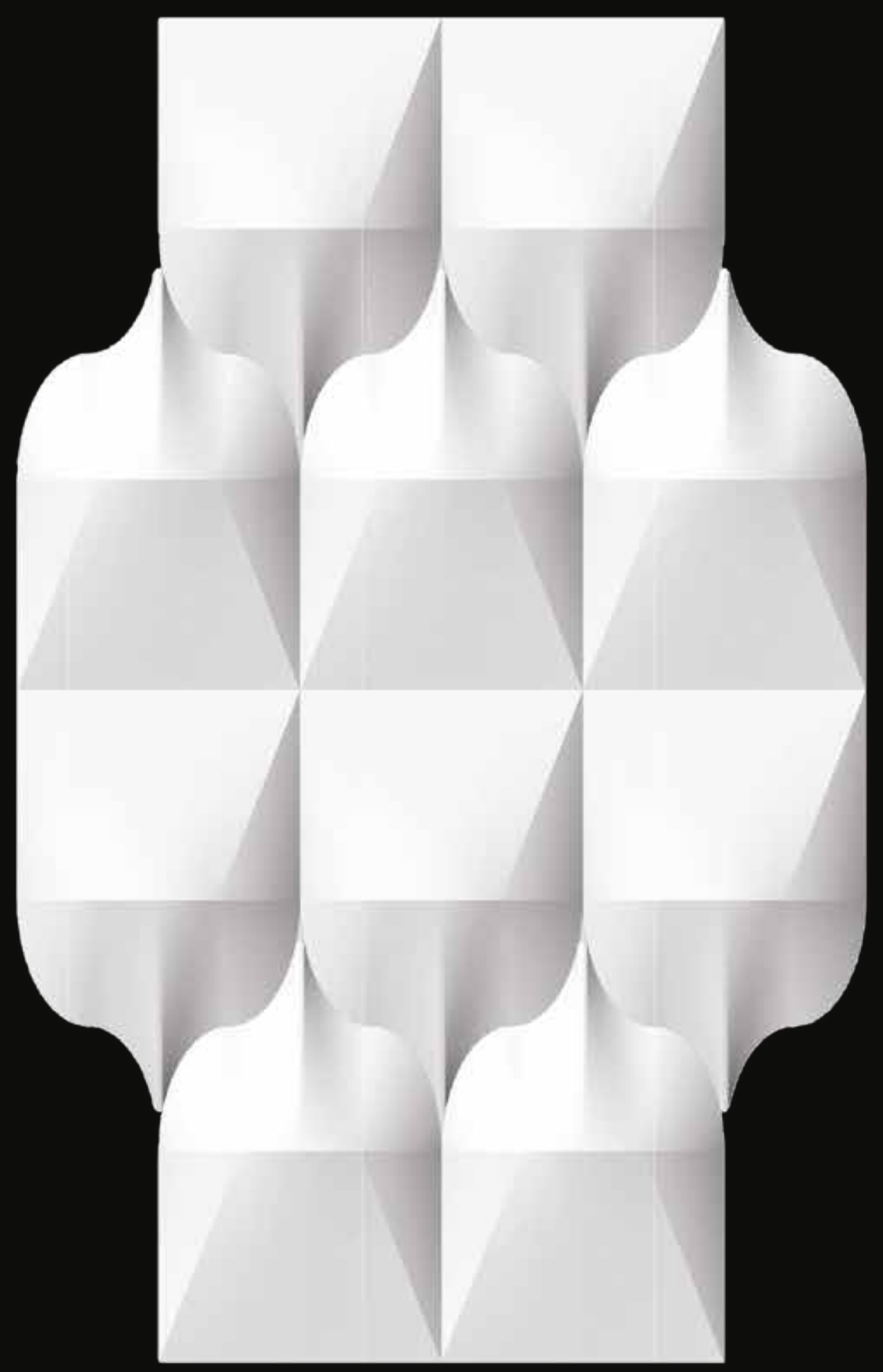



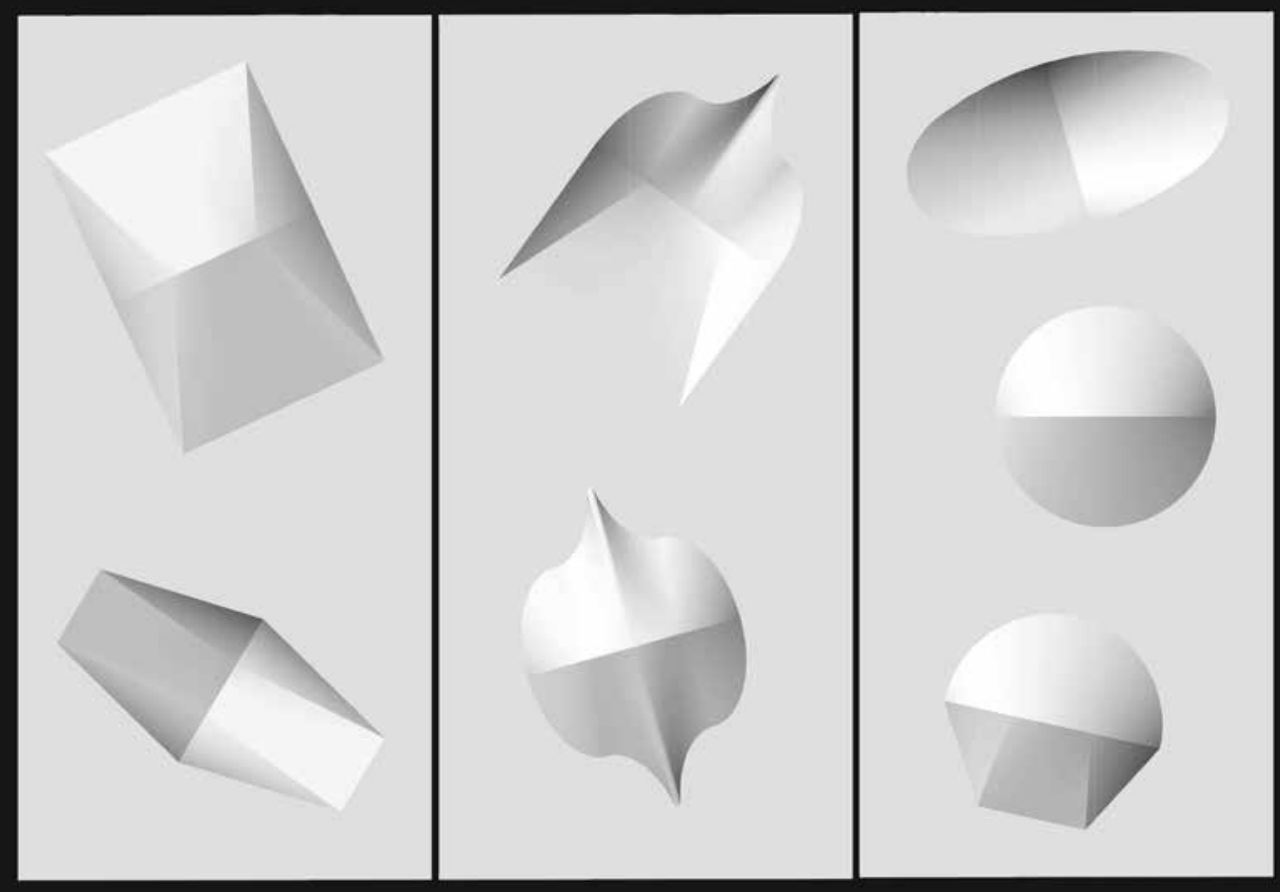

Figure 9: If either an electromagnet or weight bag fixity method can be made workable, complex and site-designated deformation of larger panels would be possible, putting both placement and deformation depth at the discretion of the tool user. Source: author. 


\section{Bibliography}

Ayres, Phil, and Bob Sheil. 2012. "Microstructure, Macrostructure, and the Steering of Material Proclivities." In Manufacturing the Bespoke: Making and Prototyping Architecture, 220-37. Chichester, U.K.: John Wiley and Sons.

Carpenter, William J., and Dan Hoffman. 1997. Learning by Building: Design and Construction in Architectural Education. New York: Van Nostrand Reinhold.

Conrad, Dale Dougherty. 2017. FREE TO MAKE: How the Maker Movement Is Changing Our Schools, Our Jobs, and Our Minds. Place of Publication Not Identified: READHOWYOUWANT COM.

Elkin, Daniel, Gerhard Bruyns, and Peter Hasdell. 2018. "Appropriate Construction Technologies for Design Activism: Material Research Practices in Response to Globalisation." Architectural Research Quarterly 22, no. 4: 290-309. doi:10.1017/s1359135518000507.

Elkin, Daniel. 2018. "Undevelopable: Metal, Curvature, and Tooling-Based Research in Hong Kong's Compressed Space." In 2018 Architecture and Civil Engineering Conference. Proceedings of Architectural and Civil Engineering Conference, Singapore. doi: 10.5176/2301-394X_ACE18.114.

Fichter, Robert, John F.C. Turner, and Peter Grenell. 1972. “The Necessity for Networks." In Freedom to Build: Dweller Control of the Housing Process, by John F. C. Turner and Robert Fichter, 255-274. New York: Macmillan.

Ganesan, Hall, Chiang, Hall, G, and Chiang, Y. H. 1996. Construction in Hong Kong: Issues in Labour Supply and Technology Transfer. Aldershot; Hong Kong: Avebury.

Civil Engineering and Development Department. “Improvement Works at Tai O." Improvement Works at Tai O - Index. Accessed October 13, 2018. https://www. revitalization-taio.com/en/index.html.

Civil Engineering and Development Department. Hong Kong Special Administrative Region. Hong Kong Government. 2017. Sustainable Lantau Blueprint. Hong Kong, HKSAR: Hong Kong Government.

Lands Department. Hong Kong Special Administrative Region. Squatter Control Office. 2016. Squatter Control Policy on Surveyed Squatter Structures. Hong Kong: Government of the Hong Kong Special Administrative Region.

Leung, David C.F. 2002. Rebuilding Community Spirit: Developing a Communal Reconstruction Strategy in the Village of Tai $O$, Hong Kong. Master's thesis, Dalhousie University, 2002. Halifax, Nova Scotia: Dalhousie University.

Lipton, Tom. 2009. Metalworking Sink or Swim: Tips and Tricks for Machinists, Welders, and Fabricators. New York: Industrial Press.
Mallett, Jessica, writer. 2011. "Mythbusters Torpedo Tastic.” In Mythbusters. Discovery Channel.

Pye, David. 2015. The Nature and Art of Workmanship. New York: Bloomsbury.

Roser, Christoph. 2017. "Faster, Better, Cheaper" in the History of Manufacturing: From the Stone Age to Lean Manufacturing and beyond. Boca Raton, FL: CRC Press.

Turner, John F.C. 1972. "The Problem of Standards." In Freedom to Build: Dweller Control of the Housing Process, by John F. C. Turner and Robert Fichter, 1-21. New York: Macmillan.

Werlin, Herbert. 1999. “The Slum Upgrading Myth." Urban Studies 36, no. 9: 1523-534. doi:10.1080/0042098992908.

West, Mark, and Bob Sheil. 2012. "The Projective Cast." In Manufacturing the Bespoke: Making and Prototyping Architecture, 132-45. Chichester, U.K.: John Wiley and Sons.

Wong, Wai King. 2000. Tai O Love Stories of the Fishing Village. Hong Kong: Concern Group About Tai O's Culture and Antiquities.

\section{Bio}

Daniel Elkin is a designer and builder working in Hong Kong. Elkin is an assistant professor of Environmental Design and Technical Coordinator for the Department of Environment and Interior Design at The Hong Kong Polytechnic University. His work focuses on spatial agency and its relationships with material practice, tooling, and construction technology. His work has been published in the journal Architectural Research Quarterly, at the College Art Association Annual Conference, and in a number of popular publications. His recent research studies stilt house communities in Hong Kong and Southeast Asia, studying intersections between community development, individual development decisions, and owner-builder construction technology. He has masters of architecture degrees from Cranbrook Academy of Art, and the University of Cincinnati. 